\title{
Anwenderfreundlich und effizient
}

SpeedCEM Plus ist ein selbstadhäsiver, selbsthärtender Komposit-Zement mit optionaler Lichthärtung. Mit seiner optimierten Rezeptur eignet er sich besonders für Restaurationen aus Zirkoniumoxid und aus Metallkeramik, außerdem für die Befestigung von Restaurationen auf Implantat-Abutments. Bei der Befestigung opaker oder lichtundurchlässiger Restaurationen bedeutet eine starke Selbsthärtung zusätzliche Sicherheit bei der Befestigung. Das Material erreicht seine hohen Haftkräfte auf Zirkoniumoxid, auf Nichtedelmetallen - wie z. B. Titan - sowie auf Dentin auch ohne Lichthärtung.

Dank optionaler Lichthärtung lassen sich Überschüsse nach kurzem Anhärten in großen Teilstücken leicht entfernen. Zudem erlaubt der Zement die flexible Nutzung in unterschiedlichen Situationen. Er erreicht einen sicheren Verbund auf feuchtem und auf trockenem Dentin sowohl bei Selbst- als auch bei Lichthärtung. Dank hoher Röntgenopazität ist der Zement gut von Schmelz und Dentin unterscheidbar. Dies erleichtert eine nachträgliche Röntgendiagnose von verbliebenen Zementüberschüssen und von Sekundärkaries. Dank der selbstadhäsiven Eigenschaften kann auf die Ätzung mit Phosphorsäure und die Verwendung von Dentinadhäsiven verzichtet werden. Für die Befestigung von Restaurationen aus Zirkoniumoxid oder edelmetallfreien Legierungen wird kein zusätzlicher Primer benötigt. Für die besonders effiziente Reinigung speichelkontaminierter Restaurationen nach der Einprobe empfiehlt sich die Verwendung von Ivoclean.

Nach einer Pressemitteilung der Ivoclar Vivadent GmbH, Ellwangen (Jagst) www.ivoclarvivadent.de 